\title{
CANCER OF THE ORGANS OF THE REPRODUCTIVE SYSTEM IN WOMEN WITH TYPE 2 DIABETES. EFFECTS OF ANTIDIABETIC THERAPY
}

DOI: 10.36740/WLek202005124

\author{
Tamara S. Vatseba \\ DEPARTMENT OF ENDOCRINOLOGY, IVANO-FRANKIVSK NATIONAL MEDICAL UNIVERSITY, IVANO-FRANKIVSK, UKRAINE
}

\begin{abstract}
The aim: to investigate the prevalence of cancer of the reproductive system in women with type 2 diabetes, and to examine the impact of antidiabetic therapy on cancer risk of this localization.

Materials and methods: The study included a retrospective analysis of medical records of women with T2D with first diagnosed cancer during 2012-2016. The bases for the study were specialized medical institutions in Ivano-Frankivsk region. The obtained results were processed using statistical programs "Microsoft Excel" and "Statistika-12". Results: Breast, uterine, and ovarian cancer were detected in 202 postmenopausal women, $63.92 \%$ from the total number of cancer cases in women. An increased risk of breast $[O R=1.24 ; 95 \% \mathrm{Cl}(1.04-1.50) \mathrm{P}=0.019]$ and uterine cancer $[0 \mathrm{R}=1.32 ; 95 \% \mathrm{Cl}(1.02-1.69) \mathrm{P}=0.040]$ has been identified. Most often, before the detection of cancer, women received combination therapy with sulfonylurea and metformin ( 83 patients $(57.64 \%)$ ) with BMI $32.64 \pm 3.69 \mathrm{~kg} / \mathrm{m}^{2}$. The difference between risk of cancer on metformin monotherapy and on sulfonylurea monotherapy $[O R=2.17 ; 95 \% \mathrm{Cl}(0.88-5.36) \mathrm{P}=0.141]$ or on combination therapy $[\mathrm{OR}=1.68 ; 95 \% \mathrm{Cl}(0.76-3.74) \mathrm{P}=0.276]$ was not found. Conclusions: Postmenopausal women have an increased risk of breast and uterine cancer and are recommended to be screened for these diseases. The highest incidence of cancer in women with obesity on combination therapy requires the use of antidiabetic drugs that are able to correct BMI as a second-line therapy.
\end{abstract}

KEY WORDS: diabetes, woman, cancer, reproductive system `s organs

Wiad Lek. 2020;73(5):967-971

\section{INTRODUCTION}

The increased risk of cancer of the organs of the reproductive system (ORS) in women with type 2 diabetes mellitus (T2D) explains the relevance of the search for mechanisms of association between these two diseases. Clinical studies prove the influence of pathogenetic factors of $\mathrm{T} 2 \mathrm{D}$ on the development of breast, uterine and ovarian cancer [1]. A particularly important role in the genesis of these oncological diseases is given to obesity due to dysmetabolic and dishormonal disorders associated with it $[2,3,4]$. In diabetes and obesity, the synergistic effects of hyperinsulinemia and hyperestrogenia in stimulating proliferative processes in hormone-dependent organs have been proved [5]. Hyperglycaemia is a potent factor in oncogenesis [6].

Given the chronic course of diabetes and the need for daily treatment, there is a clear interest in the study of cancer-related properties of antidiabetic drugs (ADD) (pro-oncogenic and cancer-protective). Due to the ability of ADD to reduce glycaemia, all groups of these drugs suppress the processes of carcinogenesis caused by hyperglycaemia. On the other hand, the various mechanisms of action of ADD cause additional cancer-related pleiotropic effects, due to their modifying effects on diabetes-dependent cancer risk factors. Separate studies have shown that prolonged treatment with high doses of pioglitazone may increase the risk of bladder cancer [7]. The use of dipeptidyl peptidase-4 (DPP-4) inhibitors and possibly agonists of glucagon-like peptide-1 (GLP-1) as secondor third-line antidiabetic therapy (ADT) may increase the risk of cholangiocarcinoma in adults with T2D [8]. The analysis by Chen Y. and co-investigators presents the results of cohort and case-control studies on the increase in oncological risk in patients treated with sulfonylurea derivatives (SUD) compared to those on metformin. At the same time, in a randomized controlled trial (involved in this analysis) cancer incidence did not depend on the use of insulin synthesis stimulants [9].

However, most of the scientific discussions are related to the cancer-protective properties of metformin. A possible exaggeration of the antitumor properties of metformin is discussed in the work of Suissa S. and Azoulay L. [10]. According to Pollak et al., metformin exerts an anticancer effect only by significantly higher doses than traditionally used [11]. A large number of studies confirm the cancer-protective properties of metformin. An analysis of 12 randomized controlled trials and 41 observational studies conducted by Monica Franciosi and co-investigators demonstrated the ability of metformin to reduce cancer-related mortality and risk of certain types of cancer in people with T2D. However, no positive correlation be- 
tween metformin therapy and risk of breast, lung, ovarian, uterine, prostatic, bladder, kidney cancer and melanoma was found [12].

\section{THE AIM}

The aim is to investigate the prevalence of cancer of the organs of the reproductive system in women with type 2 diabetes, and to examine the impact of antidiabetic therapy on cancer risk of this localization.

\section{MATERIALS AND METHODS}

The study was conducted in accordance with the guidelines of the Declaration of Helsinki (1975) and its revised version of 1983. The study included a retrospective analysis of medical records of women with T2D, with first diagnosed cancer during 2012-2016. The bases for the study were Precarpathian Oncology Center, Regional Clinical Hospital of Ivano-Frankivsk and other specialized medical institutions of Ivano-Frankivsk region.

The obtained results were processed using statistical programs "Microsoft Excel" and "Statistika-12". The arithmetic

Table I. Spectrum and frequency of cancer in women with T2D.

\begin{tabular}{|c|c|c|}
\hline Localization & $\begin{array}{l}\text { Number of patients } \\
\qquad(n=316)\end{array}$ & $\begin{array}{c}\text { Frequency } \\
\text { (\%) }\end{array}$ \\
\hline Breast cancer & 126 & 39.87 \\
\hline Colorectal cancer & 28 & 8.86 \\
\hline Uterine cancer & 65 & 20.57 \\
\hline Pancreatic cancer & 24 & 7.59 \\
\hline Skin cancer & 21 & 6.65 \\
\hline Gastric cancer & 8 & 2.53 \\
\hline Ovarian cancer & 11 & 3.48 \\
\hline Kidney cancer & 5 & 1.58 \\
\hline Thyroid gland cancer & 5 & 1.58 \\
\hline $\begin{array}{c}\text { Cancer of other } \\
\text { localizations: biliary } \\
\text { tract, lungs, external } \\
\text { female genital organs, } \\
\text { sinuses of the nose, } \\
\text { soft tissues, salivary } \\
\text { glands, urinary tract, } \\
\text { lymphoma. }\end{array}$ & 23 & $\begin{array}{c}7.28 \\
(<1.5 \text { each of } \\
\text { the cancers in } \\
\text { particular })\end{array}$ \\
\hline
\end{tabular}

Note: $1 . \%$ - for all women with cancer and T2D. mean (M), standard error (m), standard deviation (SD), number of variant (n) were used to represent the results. Differences between values were determined using the Student's t-test. The differences were considered significant at $\mathrm{P}<0.05$. The Odds ratio (OR), 95\% confidence interval, the positive and negative predictive value were calculated to determine the risk of predicted events. The study protocol was reviewed and approved by the Ethics Committee of the University of Ivano-Frankivsk National Medical University (protocol No. 97/17 of October 19, 2017).

\section{RESULTS AND DISCUSSION}

According to the results obtained, 316 women with T2D were first diagnosed with cancer during 2012-2016. Most frequent were breast, uterine, colorectal, pancreatic and skin cancer (Table I).

According to the Table I, ORS cancer was detected in 202 women $(63.92 \%)$, cancer of other localizations in 114 women (36.08\%). Considering the number of women with T2D in the Ivano-Frankivsk region, as well as those with cancer (during 2012-2016), by the statistical odds ratio method, an increased risk of malignant neoplasms (MN) of the breast and uterus in woman with T2D was identified and confirmed (Table II).

The analysis of the ADT of patients before detection of cancer was carried out. Women with MN of ORS most frequently were on metformin (15.35\%), SUD monotherapy $(14.85 \%)$ and a combination of these drugs (41.09\%). A lot of patients were on diet therapy (13.37\%) (Table III).

A statistical evaluation of the prevalence of the most common types of ADT in women before the detection of ORS cancer has been performed. It was found that the patients most often were on combination therapy involving SUD and metformin - 83 people, less frequently on metformin monotherapy - 31 women, and SUD monotherapy - 30 patients (Table IV).

The clinical characteristics of patients with cancer of ORS, depending on the prescribed therapy, are shown in Table V.

The comparison of the risk of cancer of the ORS in women with T2D on the most common schemes of ADT: metformin monotherapy, SUD monotherapy and combination therapy (Metformin + SUD) (Table VI).

According to the obtained results, the risk of cancer of the ORS on SUD monotherapy and on combination therapy did not differ from the oncological risk on metformin monotherapy $(\mathrm{P}>0.05)$ (Table VI).

Table II. Assessment of cancer risk in woman with T2D.

\begin{tabular}{|c|c|c|c|c|c|c|c|}
\hline \multirow[t]{2}{*}{ Localization of MN } & \multicolumn{2}{|c|}{$\begin{array}{c}\text { The number of women } \\
\text { with T2D }\end{array}$} & \multicolumn{2}{|c|}{$\begin{array}{c}\text { The number of women of the } \\
\text { age of }>35 \text { without T2D }\end{array}$} & \multirow[t]{2}{*}{ OR } & \multirow[t]{2}{*}{$95 \% \mathrm{Cl}$} & \multirow[t]{2}{*}{$\mathbf{P}$} \\
\hline & Total & With MN & Total & With MN & & & \\
\hline Breast cancer & 26918 & 126 & 421232 & 1580 & 1.25 & $1.04-1.50$ & $P=0.019$ \\
\hline Uterine cancer & 26918 & 65 & 421232 & 774 & 1.31 & $1.02-1.69$ & $P=0.040$ \\
\hline Ovarian cancer & 26918 & 11 & 421232 & 513 & 0.34 & $0.18-0.61$ & $P>0.05$ \\
\hline
\end{tabular}

Note: OR - the odds ratio; $95 \%$ Cl - 95\% confidence interval. 
Table III. Antidiabetic therapy of patients with T2D before diagnosis of cancer of reproductive system `s organs.

\begin{tabular}{|c|c|c|c|c|}
\hline \multirow{3}{*}{ Antidiabetic therapy } & \multirow{2}{*}{\multicolumn{2}{|c|}{$\begin{array}{c}\text { Cancer of the ORS } \\
\text { Number of patients }(n=202)\end{array}$}} & \multirow{2}{*}{\multicolumn{2}{|c|}{$\begin{array}{l}\text { Cancer of other localizations } \\
\text { Number of patients }(n=114)\end{array}$}} \\
\hline & & & & \\
\hline & Absol. & $\%$ & Absol. & $\%$ \\
\hline Diet & 27 & 13.37 & 10 & 8.77 \\
\hline Metformin & 31 & 15.35 & 10 & 8.77 \\
\hline SUD & 30 & 14.85 & 21 & 18.42 \\
\hline Glitazones & 1 & 0.50 & 0 & 0.00 \\
\hline Insulin & 12 & 5.94 & 11 & 9.65 \\
\hline Metformin + SUD & 83 & 41.09 & 45 & 39.47 \\
\hline Metformin + DPP- 4 inhibitors & 2 & 0.99 & 2 & 1.75 \\
\hline Metformin + Gliflozines & 2 & 0.99 & 0 & 0.00 \\
\hline Metformin + Insulin & 12 & 5.94 & 13 & 11.40 \\
\hline Metformin + SUD + DPP-4 inhibitors & 1 & 0.50 & 0 & 0.00 \\
\hline SUD + insulin & 1 & 0.50 & 2 & 1.75 \\
\hline
\end{tabular}

Note: $1 . \%$ - in relation to women with T2D and cancer of RSO and other localizations.

Table IV. Frequency of use of the most common types of antidiabetic drugs in women with cancer of the organs of the reproductive system, $(n=144)$.

Type of ADD

Frequency $(\mathrm{M} \pm \mathrm{m})$

\section{Metformin monotherapy} $(n=31)$
SUD monotherapy $(\mathrm{n}=30)$
Metformin + SUD $(\mathbf{n}=83)$

$20.83 \pm 3.47^{*}$

Note: ${ }^{*}$ - the rate is significantly lower compared to the group of patients on combination therapy.

Table V. Clinical characteristics of patients depending on the type of antidiabetic drugs, $(n=144)$.

\begin{tabular}{cccc}
\hline Type of ADD & $\begin{array}{c}\text { Metformin monotherapy } \\
(\mathbf{n}=\mathbf{3 1})\end{array}$ & $\begin{array}{c}\text { SUD monotherapy } \\
(\mathbf{n}=\mathbf{3 0})\end{array}$ & $\begin{array}{c}\text { Metformin + SUD } \\
(\mathbf{n}=\mathbf{8 3})\end{array}$ \\
\hline Age, years & $65.29 \pm 6.11$ & $60.70 \pm 7.39^{*}$ & $60.90 \pm 7.84^{*}$ \\
\hline BMl, $\mathrm{kg} / \mathrm{m}^{2}$ & $33.67 \pm 3.92$ & $27.66 \pm 3.02^{*}$ & $32.64 \pm 3.69$ \\
\hline Duration of DM, years & $5.77 \pm 3.39$ & $7.43 \pm 3.17$ & $8.79 \pm 5.16 \#$ \\
\hline HbA1c, \% & $8.39 \pm 1.16$ & $8.45 \pm 1.21$ & $8.36 \pm 1.06$ \\
\hline
\end{tabular}

Note. $1 .{ }^{*}$ - the indicator significantly lower than in the metformin monotherapy group $(P<0.05)$; \# - the indicator significantly higher than in the metformin monotherapy group $(\mathrm{P}<0.05)$.

Table VI. Assessment of cancer risk of reproductive system 's organs in women with T2D at different antidiabetic drugs schemes.

\begin{tabular}{ccccccccccc}
\hline ADD & Total & $\begin{array}{c}\text { With } \\
\text { cancer of } \\
\text { ORS }\end{array}$ & $\begin{array}{c}\text { Without of } \\
\text { cancer } \\
\text { of ORS }\end{array}$ & ADD & Total & $\begin{array}{c}\text { With } \\
\text { cancer of } \\
\text { ORS }\end{array}$ & $\begin{array}{c}\text { Without of } \\
\text { cancer } \\
\text { of ORS }\end{array}$ & $\begin{array}{c}\text { OR } \\
\text { CR }\end{array}$ \\
\hline Metformin & 41 & 31 & 10 & SUD & 51 & 30 & 21 & 2,17 & $0,88-5,36$ & $P=0,141$ \\
\hline Metformin & 41 & 31 & 10 & $\begin{array}{c}\text { Metformin }+ \\
\text { SUD }\end{array}$ & 128 & 83 & 45 & 1,68 & $0,76-3,74$ & $P=0,276$ \\
\hline
\end{tabular}

Note: $0 \mathrm{R}$ - the odds ratio; $95 \% \mathrm{Cl}$ - 95\% confidence interval.

The results of the study confirm the high prevalence and increased risk of cancer of the ORS in women with T2D (Tables I, II). The high incidence of cancer of these localizations is due to the influence of pathogenetic factors of diabetes and their ability to cause dysmetabolic and dyshormonal changes that activate proliferative processes in this organs. Many studies have shown an increased risk of these cancers in patients with T2D [13]. Presented in Table III kinds of ADD before the diagnosis of cancer demonstrate the traditional methods of the treatment of patients with T2D in clinical practice, particularly during the study period. According to the analysis, patients were mostly on metformin (15.35\%), sulfonylureas monotherapy (14.85\%), and on their combination (41.09\%). It should be noted that among 202 women with diabetes and ORS cancer, 27 were on diet therapy (13.37\%), prompting the need for closer metabolic control of these patients, in addition to glycaemic control. 
Significantly higher frequency of the use of combination therapy was found compared to metformin $(t=6.61 ; \mathrm{P}<0.001)$ and SUD monotherapy $(\mathrm{t}=6.77 ; \mathrm{P}<0.001)$ (Table IV).

According to the data of Table V, overweight patients (BMI $\left.=33.67 \pm 3.92 \mathrm{~kg} / \mathrm{m}^{2}\right)$ with short duration of diabetes $(5.77 \pm$ 3.39 years) were on metformin monotherapy; patients without obesity (BMI $27.66 \pm 3.02 \mathrm{~kg} / \mathrm{m}^{2}$ ) with disease duration $7.43 \pm 3.17$ years were on SUD monotherapy. The clinical characteristics of women, who received combination therapy (83 patients (41.09\%)), confirmed the presence of obesity and probable insulin resistance associated with it $(\mathrm{BMI}=32.64 \pm$ $\left.3.69 \mathrm{~kg} / \mathrm{m}^{2}\right)$. The duration of diabetes in women in this group was $8.79 \pm 5.16$ years.

The choice of SUD as a second-line drug for the correction of hyperglycaemia is quite popular among medical prescription in many countries, as well as in Ukraine. Clinical characteristics of patients also serve as a basis for considering the need to prefer drugs of other groups (incretins, glyphlozines, a-glucosidase blockers) for the purpose of body weight correction, since effect of obesity on the development of breast, endometrial and ovarian cancer has been proved [2, 3, 4]. Currently, it is likely that the spectrum of ADD in medical prescriptions has become more diverse, but the data presented may be useful for future conclusions. The findings confirm the prevalence of ORS cancer in postmenopausal women (Table V), which on the one hand confirms the link between aging and cancer, and on the other, is explained by the dishormonal effects caused by obesity and diabetes. It is known that in the postmenopausal period, peripheral synthesis of female sex hormones is predominant. Obesity promotes the conversion of androgen precursors to oestrogens, and facilitates their interaction with receptors of hormone-dependent target organs. Another mechanism that increases the level of free peripheral sex hormones is a decrease in the content of sex hormone binding globulin (SHBG), due to hyperinsulinemia - a pathogenetic factor of $\mathrm{T} 2 \mathrm{D}$ and a potent factor in the oncogenesis of the ORS.

The direct dependence of free sex hormones on BMI in post-menopausal women has been proved. Estradiol has been found not only to accelerate endometrial cell proliferation and inhibit apoptosis, but also to stimulate local IGF-1 synthesis in endometrial tissue. Thus, under the influence of elevated estrone concentrations caused by both obesity and hyperinsulinaemia, in the endometrium IGF-1 expression is increased. It has now been proven that insulin and IGF- 1 are able to directly stimulate endometrial proliferation without oestrogen involvement. In addition, both IGF- 1 and oestrogens can simultaneously activate the early responses of some oncogenes involved in the regulation of cellular growth, indicating a synergism of their action. That is, IGF-1 supports oestrogen-dependent endometrial proliferation [14].

In addition, the ability of insulin to cause its own mitogenic effects and to potentiate the proliferative effect of IGF-1 is known [15]. Chronic hyperglycaemia has an undeniable carcinogenic effect due to genomic mutations caused by oxidative stress, as well as due to its indirect effect on the synthesis of cytokines and growth factors [16].

A comparative analysis of the risk of the development of cancer of the ORS of women with T2D, depending on the type of ADT, was carried out, taking into account the most commonly used methods of treatment. According to the results obtained, the risk of cancer of ORS does not differ in patients receiving metformin monotherapy, SUD monotherapy or combination therapy. The data are consistent with the findings of Franciosi et al. [12], as well as with conclusions of other studies [17], but differ from meta-analyses and large-scale studies that suggest metformin to reduce the risk of cancer of certain localizations, includinglung [18], colorectal [19], ovarian [20], breast [21] and endometrial cancer [22].

Although the results obtained differ from many others studies, cancer-protective properties of metformin are proved, especially those on the molecular level [23]. The overall positive effect of metformin is due to its ability to reduce insulin and IGF-1 levels, which activate one of the most important intracellular signalling pathways - PI3K/Akt/mTOR. Metformin has also the ability to correct the activity of mTOR, a key carcinogenesis kinase, through stimulation of hepatic kinase B1 (LKB1), which phosphorylates and activates adenosine monophosphate protein kinase (AMPK) - the main inhibitor of mTOR and dependent on it p70S6K and eucariotic factor of translational initiation 4EBP1 (4E-binding protein 1) [24]. Metformin inhibits the activation of nuclear kappa-bi factor (NF-kB), a transcription factor that controls the expression of immune response, apoptosis and cell cycle genes, and inhibits Stat3 signalling in cancer stem cells, reducing the increase in inflammatory responce and the intensity of the tumor growth [25]. Cancer-protective effects of metformin can also be considered with its ability to positively influence the composition of the gut microbiota, increasing the content of gram-positive bacteria (capable of inhibiting NF- $\mathrm{kB}$ ). Metformin positively alters the composition and function of the microbiota [26].

By reducing insulin content, metformin reduces the level and effect of free sex hormones due to increased SHBG. In addition, the synergistic effect of metformin and progestins on inhibiting the expression of glyoxylase, a marker of progestin resistance in endometrial cancer, has been proved [27]. Metformin regulates the expression of progestin receptors in endometrial cells also through mTOR inhibition [28].Thus, it can be stated that the cancer-protective effect of metformin is due to a combination of its direct antihyperglycemic effect and pleiotropic effects involved in the molecular mechanisms of carcinogenesis. The studying of additional properties of this drug remains relevant.

The study confirmed the high incidence and increased risk of cancer of ORS in women with T2D. Frequent addition of SUD to metformin in postmenopausal women with obesity, as well as high cancer rates of ORS in patients with this therapy are the basis to advantage as a second-line therapy ADD with the ability of correction of BMI, insulin content and other metabolic parameters. More accurate answers to the questions related to the study can be obtained by careful registration of cancer cases in patients with diabetes that are treated with different types of ADT.

\section{CONCLUSIONS}

Postmenopausal women with diabetes mellitus 2 are at increased risk of breast and uterine cancer and require to be timely screened for these diseases. Most often, cancer of the organs of the reproductive system was diagnosed in patients on combina- 
tion therapy involving metformin and sulphonylureas. The risk of developing cancer of the organs of the reproductive system on metformin monotherapy was not significantly different from the risk on the sulfanilureas monotherapy or combination therapy. The highest incidence of cancer in women with obesity on combination therapy encourages the wider use of drugs with the ability to correct body weight.

\section{REFERENCES}

1. García-Jiménez C., Gutiérrez-Salmerón M., Chocarro-Calvo A., et al. From obesity to diabetes and cancer: epidemiological links and role of therapies. Br J Cancer. 2016;114(7):716-722.

2. Engin A. Obesity-associated Breast Cancer: Analysis of risk factors. Adv Exp Med Biol. 2017;960:571-606.

3. Foong K.W., Bolton H. Obesity and ovarian cancer risk: A systematic review. Post Reprod Health. 2017;23(4):183-198.

4. Shaw E., Farris M., McNeil J., Friedenreich C. Obesity and Endometrial Cancer. Recent Results Cancer Res. 2016;208:107-136.

5. Chernyshova A.L., Kolomiyets L.A., Yunusova N.V., etal.Patogeneticheskoye obosnovaniye neobkhodimosti korrektsii metabolicheskogo sindroma u bol'nykh s giperplasticheskimi protsessami i rakom endometriya [Pathogenetic foundation of metabolic syndrome correction in patients with endometrial hyperplasia and endometrial cancer]. Russian Biotherapeutics Journal. 2013;1(12): 3-10. (Ru).

6. Ramteke P., Deb A., Shepal V., Bhat M.K. Hyperglycemia Associated Metabolic and Molecular Alterations in Cancer Risk, Progression, Treatment, and Mortality. Cancers (Basel). 2019;11(9):1402.

7. Tang H., Shi W., Fu S., et al. Pioglitazone and bladder cancer risk: a systematic review and meta-analysis. Cancer Med. 2018;7(4):1070-1080.

8. Abrahami D., Douros A., Yin H., et al. Incretin based drugs and risk of cholangiocarcinoma among patients with type 2 diabetes: population based cohort study. BMJ. 2018;363:k4880.

9. Chen Y., Du L., Li L., et al. Cancer risk of sulfonylureas in patients with type 2 diabetes mellitus: Asystematic review. J Diabetes. 2017;9(5):482-494.

10. Suissa S., Azoulay L. Metformin and the risk of cancer: time-related biases in observational studies. Diabetes Care. 2012;35(12):2665-2673.

11. Pollak M.N. Investigating metformin for cancer prevention and treatment: the end of the beginning. Cancer Discov. 2012;2(9):778-790.

12. Franciosi M., Lucisano G., Lapice E., et al. Metformin therapy and risk of cancer in patients with type 2 diabetes: systematic review. PLoS One. 2013;8(8):e71583.

13. Xu H.L., Fang H., Xu W.H., et al. Cancer incidence in patients with type 2 diabetes mellitus: a population-based cohort study in Shanghai. BMC Cancer. 2015;15:852.

14. Tian W., Teng F., Zhao J., et al. Estrogen and insulin synergistically promote type 1 endometrial cancer progression. Cancer Biol Ther. 2017;18(12):1000-1010.

15. Dai C., Li N., Song G., et al. Insulin-like growth factor 1 regulates growth of endometrial carcinoma through PI3k signaling pathway in insulinresistant type 2 diabetes. Am J Transl Res. 2016;8(8):3329-3336.

16. Usman M., Volpi E.V. DNA damage in obesity: Initiator, promoter and predictor of cancer. Mutat Res. 2018;778:23-37.

17. Wen Q., Zhao Z., Wen J., et al. The association between metformin therapy and risk of gynecological cancer in patients: Two meta-analyses. Eur J Obstet Gynecol Reprod Biol. 2019;237:33-41.

18. Yao L., Liu M., Huang Y., et al. Metformin Use and Lung Cancer Risk in Diabetic Patients: A Systematic Review and Meta-Analysis. Dis Markers. 2019;2019:6230162.
19. Liu F., Yan L., Wang Z., et al. Metformin therapy and risk of colorectal adenomas and colorectal cancer in type 2 diabetes mellitus patients: A systematic reviewand meta-analysis. Oncotarget. 2017;8(9):16017-16026.

20. Tseng C.H. Metformin reduces ovarian cancer risk in Taiwanese women with type 2 diabetes mellitus. Diabetes Metab Res Rev. 2015;31(6):619-626.

21. Tseng C.H. Metformin may reduce breast cancer risk in Taiwanese women with type 2 diabetes. Breast Cancer Res Treat. 2014;145(3):785-790.

22. Tang Y.L., Zhu L.Y., LiY., et al. Metformin Use Is Associated with Reduced Incidence and Improved Survival of Endometrial Cancer: A MetaAnalysis. Biomed Res Int. 2017;2017:5905384.

23. Li M., Li X., Zhang H., Lu Y. Molecular Mechanisms of Metformin for Diabetes and Cancer Treatment. Front Physiol. 2018;9:1039.

24. PushkarevV.M., Sokolova L.K., PushkarevV.V., Tron'koN.D. Biokhimicheskiye mekhanizmy, svyazyvayushchiye diabet i rak. Deystviye metformina. [Biochemical mechanisms connecting diabetes and cancer. Effects of methormine]. Endokrynologia 2018; 23(2):167-179. (UA).

25. Hirsch H.A., lliopoulos D., Struhl K. Metformin inhibits the inflammatory response associated with cellular transformation and cancer stem cell growth. Proc Natl Acad Sci U S A. 2013;110(3):972-977.

26. Wu H., Esteve E., Tremaroli V., et al. Metformin alters the gut microbiome of individuals with treatment-naive type 2 diabetes, contributing to the therapeutic effects of the drug. Nat Med. 2017;23(7):850-858.

27. Zhang Z., Dong L., Sui L., et al. Metformin reverses progestin resistance in endometrial cancer cells by downregulating Glol expression. Int J Gynecol Cancer. 2011;21(2):213-221.

28. Xie Y., Wang Y.L., Yu L., et al. Metformin promotes progesterone receptor expression via inhibition of mammalian target of rapamycin (mTOR) in endometrial cancer cells.JSteroid Biochem Mol Biol.2011;126(3-5):113-120.

The study is a fragment of the research project "Epidemiology of oncological diseases in patients with diabetes mellitus and the effect of antihyperglycemic drugs on oncogenesis markers" (registration number 0117U005263), included into the complex research work of Ivano-Frankivsk National Medical University - "Pathogenetic mechanisms of development of changes in organs of the respiratory, endocrine, nervous systems in the modeled pathological conditions and their correction" (registration number 0117U001758).

\section{ORCID and contributorship:}

Tamara S. Vatseba - 0000-0001-7849-2242 A,B,C,D,E,F

\section{Conflict of interest:}

The Author declare no conflict of interest

\section{CORRESPONDING AUTHOR Tamara S. Vatseba \\ Ivano-Frankivsk National Medical University \\ Halytska Str., 2, Ivano-Frankivsk, 76018, Ukraine \\ tel: +380509743007 \\ e-mail: tamara.vatseba@gmail.com}

Received: 21.01 .2020
Accepted: 27.03 .2020

A - Work concept and design, B - Data collection and analysis, C - Responsibility for statistical analysis, D-Writing the article, E-Critical review, $\mathbf{F}$ - Final approval of the article 